\title{
The role of acid incubation in rapid immobilization of hydrogen-producing culture in anaerobic upflow column reactors
}

\author{
Zhen-Peng Zhang ${ }^{a, b}$, Kuan-Yeow Show ${ }^{c, *}$, Joo-Hwa Tay ${ }^{a, b}$, David Tee Liang ${ }^{b}$, \\ Duu-Jong Lee ${ }^{d}, \mathrm{Ay} \mathrm{Su}^{e}$ \\ ${ }^{a}$ School of Civil and Environmental Engineering, Nanyang Technological University, Singapore 639798 \\ ${ }^{b}$ Institute of Environmental Science and Engineering, Nanyang Technological University, Singapore 637723 \\ ${ }^{c}$ Faculty of Science, Engineering and Technology, University Tunku Abdul Rahman, 31900 Kampar, Perak, Malaysia \\ ${ }^{\mathrm{d}}$ Department of Chemical Engineering, National Taiwan University, Taipei 10617, People's Republic of China \\ eDepartment of Mechanical Engineering, Fuel Cell Center, Yuan-Ze University, Taoyuan 320, People's Republic of China
}

\section{A R T I C L E I N F O}

Article history:

Received 9 May 2008

Accepted 26 May 2008

Available online 8 August 2008

Keywords:

Hydrogen production

Granulation

Biofilm formation

Upflow Column-shaped reactor

Cell surface physicochemical

characteristics

\begin{abstract}
A B S T R A C T
An approach of acidification was examined on formation of hydrogen-producing granules and biofilms in upflow column-shaped reactors. The reactors were fed with synthetic glucose wastewater and operated at $37^{\circ} \mathrm{C}$ and pH 5.5. The acclimated anaerobic culture was inoculated in four reactors designated R1, R2, R3 and R4, with R3 and R4 filled with granular activated carbon as support medium. To unveil the roles of acidification, microbial culture in R2 and R3 was subject to an acid incubation for $24 \mathrm{~h}$ by shifting the culture $\mathrm{pH}$ from 5.5 to 2.0. The experimental results suggested that the acidification substantially accelerated microbial granulation, but not biofilm formation. Microbial activities were inhibited by the acid incubation for about $78 \mathrm{~h}$, resulting in the retarded formation of biofilms of the acidified culture. Reducing culture $\mathrm{pH}$ resulted in improvement in cell surface physicochemical properties favoring microbial adhesion and immobilization. Zeta potential increased from $-25.3 \mathrm{mV}$ to $11.9 \mathrm{mV}$, hydrophobicity in terms of contact angle improved from $31^{\circ}$ to $38^{\circ}$ and production of extracellular polymers increased from $66 \mathrm{mg} / \mathrm{g}$-VSS to $136 \mathrm{mg} / \mathrm{g}$-VSS. As a result of the formation of granules and biofilms, high hydrogen production rates of 6.98 and $7.49 \mathrm{~L} / \mathrm{Lh}$ were achieved in granule-based and biofilm-based reactors, respectively. It is concluded that acid incubation is an efficient means to initiate the rapid formation of granules by regulating the surface characteristics of microbial culture. The use of support media as starting nuclei may result in rapid formation of biofilms without the acidification.
\end{abstract}

๑ 2008 International Association for Hydrogen Energy. Published by Elsevier Ltd. All rights

reserved.

\section{Introduction}

Hydrogen has been recognized as an ideal energy carrier for the near future. Biological hydrogen production from bio- photosynthesis, photo-decomposition and anaerobic fermentation has received much attention because of environmental sustainability. Among them, the anaerobic hydrogen fermentation appears to be more favorable as hydrogen is generated

\footnotetext{
* Corresponding author. Tel.: +605 4662323x222; fax: +605 4661313.

E-mail addresses: zpzhang@pmail.ntu.edu.sg (Z.-P. Zhang), kyshow2003@yahoo.com.sg (K.-Y. Show). 0360-3199/\$ - see front matter @ 2008 International Association for Hydrogen Energy. Published by Elsevier Ltd. All rights reserved. doi:10.1016/j.ijhydene.2008.05.016
} 
at higher rates with a concomitant reduction in environmental pollutants. However, the technology is yet to compete with those commercial hydrogen production processes derived from fossil fuels in terms of cost, efficiency and reliability [1]. To enhance the production rate of biohydrogen is thus a major challenge. Previous studies indicated that hydrogen production rate was greatly influenced by reactor biomass retention [2-5]. Because of elevated biomass retention, cellimmobilized processes had been developed extensively which showed an exciting production rate of up to $15 \mathrm{~L}-\mathrm{H}_{2} / \mathrm{L} \mathrm{h} \mathrm{[2].}$

The cell immobilization processes, however, have some limitations. A major drawback is the long startup period, which generally requires a few months for complete development of granules or biofilms [6-8]. A rapid approach of acid incubation to initiating the formation of hydrogen-producing granules was successfully developed in the laboratory [9]. In the study, hydrogen-producing granules were formed rapidly in an anaerobic continuous stirred tank reactor (CSTR) within around 5 days as seed culture was subjected to a 24-h period of acid incubation at a $\mathrm{pH}$ of 2.0. Obviously, the culture operating conditions of a CSTR (well mixed) were quite different from upflow column-shaped reactors (plug flow), such as upflow anaerobic sludge blanket (UASB) reactor, fixed-bed reactor and fluidized bed reactor which were most popularly used in the cell-immobilized processes. However, applicability of the acid incubation approach for microbial granulation in these column-shaped reactors remains unclear. Furthermore, the effectiveness of the approach on biofilm formation on support medium also requires validation. The lack of such information has deterred the CSTR granulation process to be developed into a practical means for microbial immobilization in other hydrogen-producing systems.

This study was initiated to further understand the role of acid incubation in stimulating microbial granulation and biofilm formation in upflow column-shaped reactors which were operated in a fluidization pattern. Granular activated carbon (GAC) was used as a support medium for biofilm growth. Changes of surface physicochemical characteristics of microorganisms during the acid incubation were monitored and the resulting effect on microbial immobilization was evaluated. Also, hydrogen production by granule-based reactor and biofilm-based reactor was assessed and compared with other cell-immobilized reactors in the literature. It is hoped that the findings derived from the present study could further extend the acid incubation approach to the entire field of cellimmobilized techniques used for biohydrogen production.

\section{Materials and methods}

\subsection{Inoculum and substrate}

Seed sludge was obtained from a local wastewater treatment plant, which was acclimated with glucose (10 g-glucose/L) in an anaerobic CSTR at pH 5.5 for more than 2 months in a previous study [10]. The acclimated sludge had a concentration of $6.1 \mathrm{~g}$-VSS/L. The substrate used for hydrogen fermentation consisted of glucose $(10 \mathrm{~g} / \mathrm{L})$ and nutrients at a constant carbon:nutrient ratio as described in the previous studies $[10,11]$.

\subsection{Experimental setup and operation}

Four identical column reactors, each mounted with a threephase separator, were operated as anaerobic fluidized bed reactors (AFBRs). The reactor consisted of a glass tubular section of $40 \mathrm{~mm}$ internal diameter and $500 \mathrm{~mm}$ height with a conical bottom (Fig. 1). An upper section of $80 \mathrm{~mm}$ internal diameter and $150 \mathrm{~mm}$ length was mounted to minimize carryover of suspended particles into the effluent which also served as a gas holder. A $40 \mathrm{~mm}$ height fixed-bed of glass beads was located at the conic bottom, serving as a distributor for incoming liquid. Each reactor had a total volume of $1.4 \mathrm{~L}$ inclusive of reaction-zone volume of $0.6 \mathrm{~L}$. The column has four sampling ports located 50,120, 250 and $400 \mathrm{~mm}$ above the reactor bottom. These ports were used to extract liquid and bioparticle samples along the reactor. The mixed slurry was recycled through a recycling pump connecting the outlet located at the settling section and feed inlet at a constant recycling rate of $200 \mathrm{~mL} / \mathrm{min}$. Culture $\mathrm{pH}$ in the reactor was controlled at $5.5 \pm 0.2$ by automatic titration using respective peristaltic pumps connecting to an integrated controller with $4 \mathrm{M}$ $\mathrm{NaOH}$ and $4 \mathrm{M} \mathrm{HCl}$. The reactors were operated at a consistent temperature of $37^{\circ} \mathrm{C}$ maintained by a heating blanket.

GAC was used as the support medium for biofilm attachment, whose physical characteristics had been described in a previous study [11]. Seventy grams of GAC was loaded for each reactor, occupying a static bed height of $130 \mathrm{~mm}$. The acclimated anaerobic culture was inoculated into four reactors (1 L, each) designated R1, R2, R3 and R4, with R3 and R4 filled

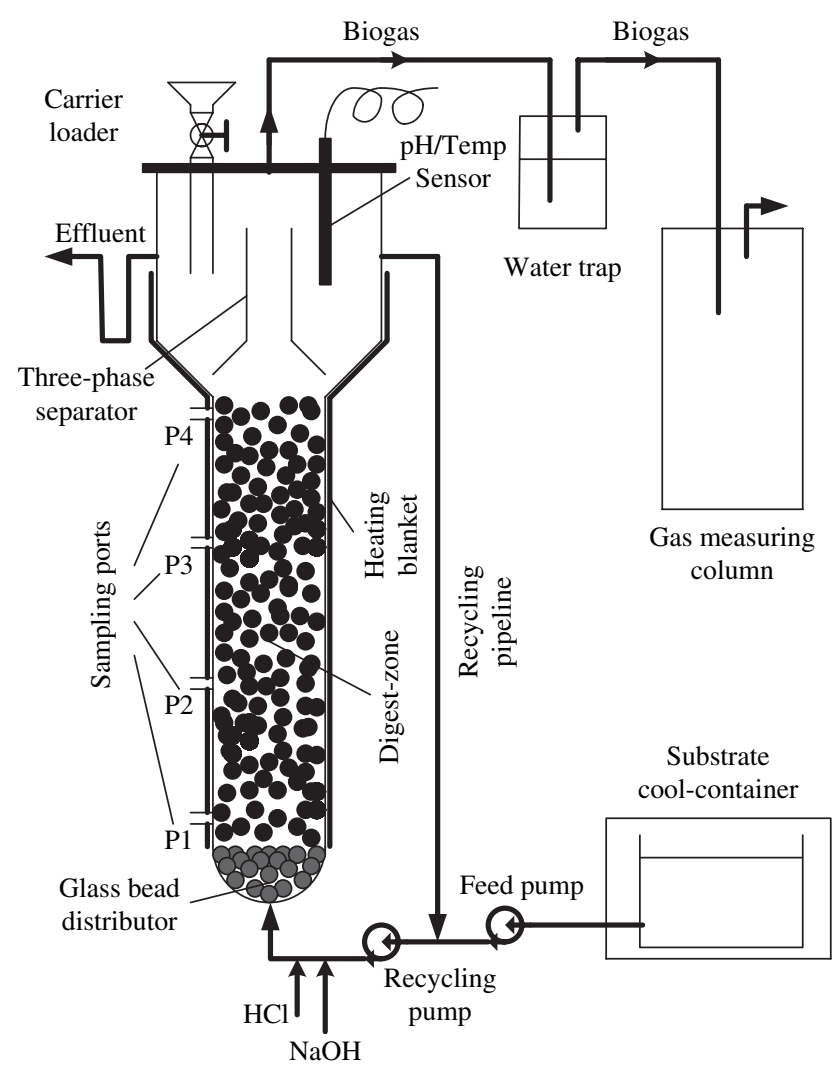

Fig. 1 - Schematic diagram of the anaerobic fluidized bed reactor system. 
with GAC as support medium. The reactors were topped up with tap water and flushed with industrial argon gas for $10 \mathrm{~min}$ to create an anaerobic environment before the startup of reactors. To evaluate the influence of acidification, the microbial culture in R2 and R3 was subject to acid incubation for $24 \mathrm{~h}$ by shifting the culture $\mathrm{pH}$ from 5.5 to 2.0 . No substrate was introduced during the period of acidification to all the reactors. The culture was returned to normal pH ( $\mathrm{pH}$ 5.5) subsequently and operated at HRTs of $12 \mathrm{~h}, 2 \mathrm{~h}, 1 \mathrm{~h}, 0.5 \mathrm{~h}$ and $0.25 \mathrm{~h}$ in series. An overview of the experimental conditions is shown in Table 1. The HRTs were calculated on the basis of the total reactor volume, while the organic loading rates (OLRs) were computed from the concentration of glucose loaded onto the reactor per unit HRT. Pseudo steady-state conditions at each HRT level were considered attained when biogas production and glucose conversion rate fluctuated within $5 \%$ for 24 consecutive HRT cycles. Evaluation of the system performance was carried out during the pseudo steadystate conditions.

\subsection{Analytical methods}

Biogas flow was measured using the water displacement method, and biogas volume was calibrated to a temperature of $25^{\circ} \mathrm{C}$ and pressure of $1 \mathrm{~atm}$ conditions. The biogas composition with respect to $\mathrm{H}_{2}, \mathrm{CO}_{2}$ and $\mathrm{CH}_{4}$ was analyzed by gas chromatography as described in the previous work $[9,10]$. Glucose concentration was determined following the phenol-sulfuric acid method reported by Dubois et al. [12]. Measurements of volatile suspended solid (VSS) were performed according to the Standard Methods [13].

Culture surface physicochemical properties including zeta potential, contact angle and extracellular polymers (ECP) composition were analyzed by a Zeta Potential Analyzer (ZetaPals, Brookhaven Instruments, Holtsville, NY), contact angle system (OCA 20, dataphysics instruments Gmbh, Filderstadt, Germany) and spectrophotometer (Jasco V-550 UV/VIS, Japan), respectively. Detailed procedures can be referred to in a previous study [9]. Sludge flocs or bioparticle size was measured by either a laser particle size analysis system (Malvern Mastersizer HYDRO2000SM, Malvern Instruments Ltd., Worcestershire, UK) or an image analysis system (Quantimet 500 Image Analyser; Leica Cambridge Instruments, Cambridge,

\section{Table 1 - Operating HRT (h) of upflow column reactors} under startup and steady-state conditions

\begin{tabular}{lcccc}
$\begin{array}{l}\text { Operating } \\
\text { time }(\mathrm{h})\end{array}$ & $\begin{array}{c}\text { R1 (control) } \\
\text { No GAC }\end{array}$ & $\begin{array}{c}\text { R2 - No } \\
\text { GAC }\end{array}$ & $\begin{array}{c}\text { R3 - } \\
\text { with GAC }\end{array}$ & $\begin{array}{c}\text { R4 - } \\
\text { with GAC }\end{array}$ \\
\hline $0-24$ & $-^{\mathrm{a}}$ & $\begin{array}{l}\text { Acid } \\
\text { incubation }^{\mathrm{a}}\end{array}$ & $\begin{array}{l}\text { Acid } \\
\text { incubation }\end{array}$ & - \\
$24-57$ & $12^{\mathrm{b}}$ & 12 & 12 & 12 \\
$58-121$ & 2 & 2 & 2 & 2 \\
$122-168$ & 1 & 1 & 1 & 1 \\
$169-193$ & 1 & 0.5 & 0.5 & 0.5 \\
$194-367$ & 1 & 0.25 & 0.25 & 0.25 \\
$368-531$ & 0.25 & 0.25 & 0.25 & 0.25 \\
\hline
\end{tabular}

a No substrate was fed.

b Operating HRT.
UK) when the particle size was beyond the Mastersizer's measurable limitation $(0.05-2000 \mu \mathrm{m})$. Microbial observation was made using the image analysis system, while the microbial compositions of granules were observed qualitatively with a scanning electron microscope (SEM) (Stereosan 420; Leica Cambridge Instruments, Cambridge, UK). Detailed protocols of sample preparation and SEM observation were reported previously by Tay et al. [14].

\section{Results and discussion}

\subsection{General observation}

All AFBRs were inoculated with acclimated hydrogen-producing sludge and started up under similar operating conditions. Fig. 2 depicts the distribution of bioparticle size in terms of volume percentage diameters ranging from $d_{0.1}$ to $d_{0.9}$ in the first $175 \mathrm{~h}$ in R1 and R2 ( $d_{\mathrm{v}}$, volume percentage diameter; $\mathrm{v}$, those particles with a diameter less than $d_{v}$ accounts for $(v / 10) \%$ of the sum of particle volume). A substantial increase in particle size with the acid incubation was noted in R2 compared with R1 whose culture was free of the acid incubation. Mean particle diameter $\left(d_{0.5}\right)$ in R2 was estimated to be $60.6 \mu \mathrm{m}$ during the acid incubation, which was much larger in contrast to the corresponding value of $26.8 \mu \mathrm{m}$ obtained in R1. This suggested that microbial aggregation occurred immediately after the acid incubation. Such rapid aggregation of microbial cells was noted and recorded microscopically in a previous study [9].
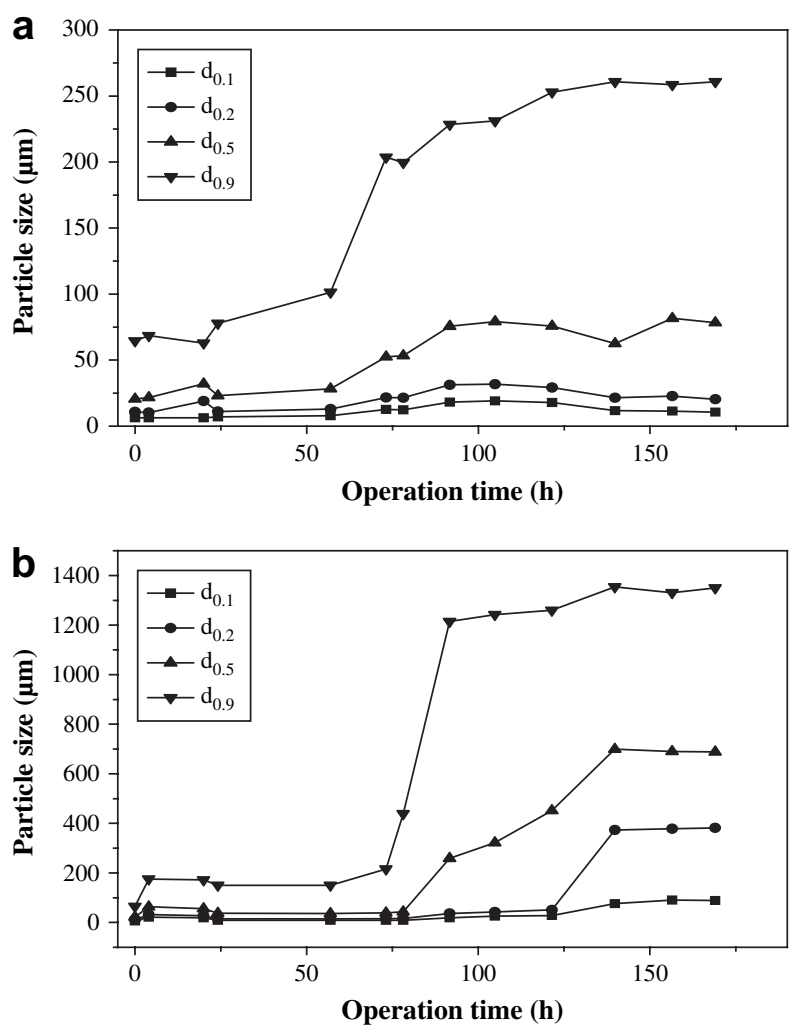

Fig. 2 - Time-course profile of bioparticle diameter (a) in R1 and (b) R2. 
Particle size increased significantly after $57 \mathrm{~h}$ of operation when the HRT was shortened from $12 \mathrm{~h}$ to $2 \mathrm{~h}$, which was generally less than $300 \mu \mathrm{m}$ in the first $330 \mathrm{~h}$ in R1 (Fig. 2a). In contrast, the particles in R2 had a mean size of $60 \mu \mathrm{m}$ in the first $78 \mathrm{~h}$, which then increased to such an extent that the diameter of some particles (10\% in volume) had exceeded $1200 \mu \mathrm{m}$ at $92 \mathrm{~h}$ (Fig. 2b). The mean diameter of particles in R2 increased from $43.27 \mu \mathrm{m}$ at $78 \mathrm{~h}$ to $698.75 \mu \mathrm{m}$ at $140 \mathrm{~h}$. Onset of granulation is subjectively defined as the formation of bioparticles having a diameter larger than $500 \mu \mathrm{m}$ based on a study reported by Show and co-workers [15]. Some granules were able to be detected at $346 \mathrm{~h}$ in R1 and a stable granular sludge layer was established until around $400 \mathrm{~h}$. In contrast, a rapid accumulation of granular sludge was noted after $92 \mathrm{~h}$ of operation in R2 due to the multiplication of granular sludge and washout of smaller suspended particles. The granular sludge layer increased significantly to a height of $14 \mathrm{~cm}$ at $120 \mathrm{~h}$ and reached the set maximum height of $48 \mathrm{~cm}$ at $153 \mathrm{~h}$. In addition, morphology of granules cultivated in R1 and R2 was rather different (Fig. 3). Compared to a spherical shape and smooth surface of granules induced by the acid incubation in R2, granules developed in R1 exhibited an irregular shape and were flocky in appearance. Although granules were accomplished in both R1 and R2, the time for granulation required in R2 was significantly reduced by nearly threefold compared to R1.

It is worth noting that no granules were formed in the CSTR without acidification of the microbial culture in the previous study [9]. Shortening HRT to $2 \mathrm{~h}$ resulted in a complete washout of microbial culture in the CSTR. Successful development of granules in R1 was presumably attributed to the columnshaped configuration of the reactor which might be in favor of biomass retention. Although the HRT was shortened to $2 \mathrm{~h}$ at which washout of suspended sludge occurred in the CSTR, a large amount of biomass, with a concentration of around $3 \mathrm{~g}$-VSS/L, and thus those attached cells formed at $36 \mathrm{~h}$ were likely due to the physical adsorption. Unlike CSTR, a continuous selection of sludge flocs occurred in the column-shaped reactors due to the hydraulic hoisting. In other words, light and dispersed sludge would be washed out, but heavier components would remain in the system. In the column-shaped reactor, the selection pressure is generally created by an upflow liquid flow pattern [16]. By dint of the hydraulic stress, methanogenic granules were successfully developed in an UASB reactor through a purely physical aggregation of anaerobic sludge [17].
Biofilm formation is deemed to occur as the support carrier is completely surrounded by continuous biofilms [18]. It was observed that continuous biofilms were first appearing on the surface of some carriers, and such biofilm-covered particles increased gradually in quantity which resulted in an increase in expanded bed height. As a result, the change of expanded bed height was monitored and considered as an index to estimate the development of biofilms.

Fig. 4 depicts the variation of expanded bed height in R3 and R4. A substantial increase in bed height occurred after $77 \mathrm{~h}$ in $\mathrm{R} 3$, whereas the GAC bed layer expanded rapidly in R4 after the feed was supplied continuously. Considering the starting time of granulation in R2 (Fig. 2b), the results indicated that a period of 77-78 $\mathrm{h}$ was likely required to activate hydrogen-producing bacteria from the acid incubation. By visual inspection, continuous biofilms were noted at around $30 \mathrm{~h}$ in $\mathrm{R} 4$. Fig. 5 illustrates several SEM images of biofilm particles sampled from the top layer of expanded bed in R3 and R4 at $36 \mathrm{~h}$. While continuous biofilms had formed in R4, no biofilm was observed visually in R3 at that time. A close examination (3000× magnification) revealed that individual cells had attached onto the surfaces as well as within the cavities of GAC. It should be realized that microbial colonization might not proceed within the first $78 \mathrm{~h}$ due to the acid incubation, and thus those attached cells at $36 \mathrm{~h}$ were likely to achieve as a result of the physical adsorption. It is interesting to find that the expanded bed reached the largest set height of $48 \mathrm{~cm}$ in R3 and R4 simultaneously after $104 \mathrm{~h}$ of operation. The effective time of biofilm development to an expansion height of $48 \mathrm{~cm}$ was estimated to be $26 \mathrm{~h}$ in R3 if an inactive period of $78 \mathrm{~h}$ was deducted, which was much shorter than $104 \mathrm{~h}$ required by $R 4$. These findings indicate that acid incubation accelerated the microbial colonization of attached hydrogenproducing bacteria once their microbial activity was resumed.

\subsection{Factors affecting cell immobilization}

\subsubsection{Roles of initial nuclei}

The physical and structural properties of particle-supported biofilms and granules are similar, as are their hydrodynamic, mass transfer and reaction characteristics $[19,20]$. Because of the absence of support carriers, establishment of such nuclei appears to be crucial to the granulation. Several researchers proposed an inert nuclei model for anaerobic granulation which had been widely accepted so far to understand
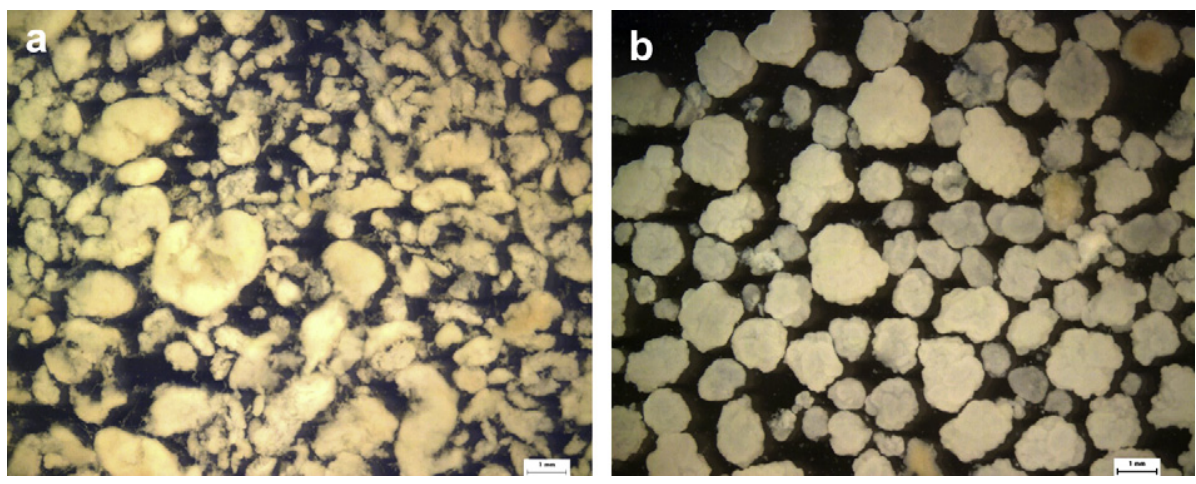

Fig. 3 - Images of initial granules developed in (a) R1 at $336 \mathrm{~h}, 10 \times$; and (b) R2 at $120 \mathrm{~h}, 10 \times$. 


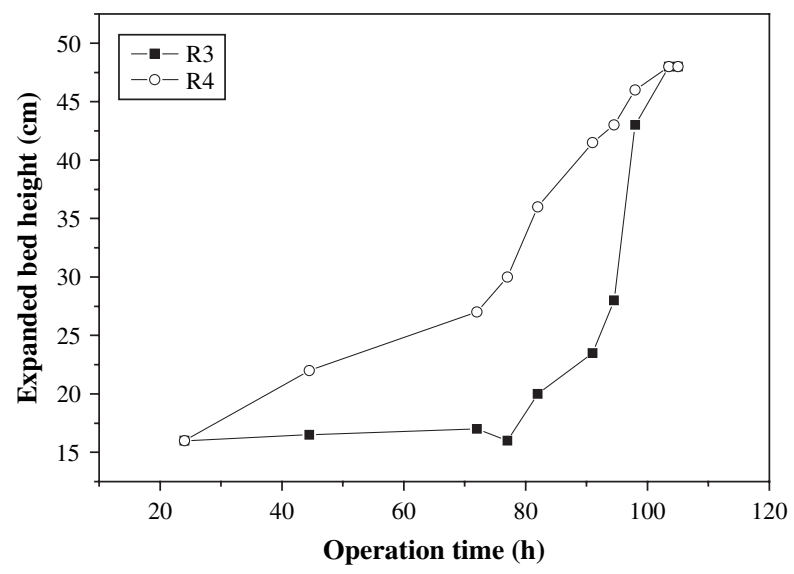

Fig. 4 - Variation of expanded bed height in R3 and R4.

microbial granulation of methanogens $[16,19,21,22]$. In this model, one of the contributing factors to the development of granules from suspended sludge is the presence of nuclei or bio-carriers for microbial attachment. Several studies had provided evidence to support the inert nuclei in enhancing anaerobic sludge granulation in the UASB reactor $[15,21,23]$.

The experimental results obtained from the present study are consistent with the reported findings. Adding GAC that served as an inert nucleus resulted in a prompt microbial colonization and biofilm development. GAC has been known as a hydrophobic sorbent favorable for cell attachment. On the other hand, acidogens are a kind of fast-growing organisms, and the maximum specific growth rate of the present culture was found to be close to $0.5 \mathrm{~h}^{-1}$ (data not shown). As a consequence, hydrogen-producing biofilms formed rapidly as observed in R4, while the development of hydrogen-producing granules was retarded substantially as observed in R1. Acid incubation significantly promoted the establishment of initial nuclei. According to the suggested size criteria of inert particles $(100-400 \mu \mathrm{m})[15,21,23]$, microbial nuclei were able to form within $10 \mathrm{~min}$ of the acid incubation as observed that at least $10 \%$ (in volume) flocs had a diameter larger than $200 \mu \mathrm{m}$ (Fig. 2b). Such microbial nuclei were not possessed in $\mathrm{R} 1$ until $72 \mathrm{~h}$ (Fig. 2a). In contrast to a period of $92 \mathrm{~h}$ required for the granulation in R2, it took a much longer time for the development of granules from these microbial nuclei in R1. Obviously, the acid incubation not only accelerated the formation of microbial nuclei, but also created a favorable niche for further development of microbial nuclei into granules.

\subsubsection{Cell surface physicochemical properties}

3.2.2.1. Surface charges. As shown in Fig. 6, zeta potential of the culture was closely related to the culture $\mathrm{pH}$. The culture zeta potential stabilized at $-25.37 \pm 1.60 \mathrm{mV}$ at a $\mathrm{pH}$ of 5.5 while a substantial increase in zeta potential was found to be $11.90 \pm 0.54 \mathrm{mV}$ as the culture $\mathrm{pH}$ was reduced to 2.0. One possible explanation for the increase in the zeta potential with reduction in $\mathrm{pH}$ is neutralization or overlaying of positive charges, i.e. $\mathrm{H}^{+}$from the acid incubation to the negative charges lying on the cell surface. It was noted that, despite the same trend of the culture zeta potential increasing with reduction in $\mathrm{pH}$, the values of culture zeta potential were different with the previous study [9] wherein the culture zeta potentials were determined to be $-11.6 \mathrm{mV}$ and $-3.5 \mathrm{mV}$ at $\mathrm{pHs}$ of 5.5 and 2.0, respectively. The most plausible factor resulting in an inconsistent observation would appear to be the
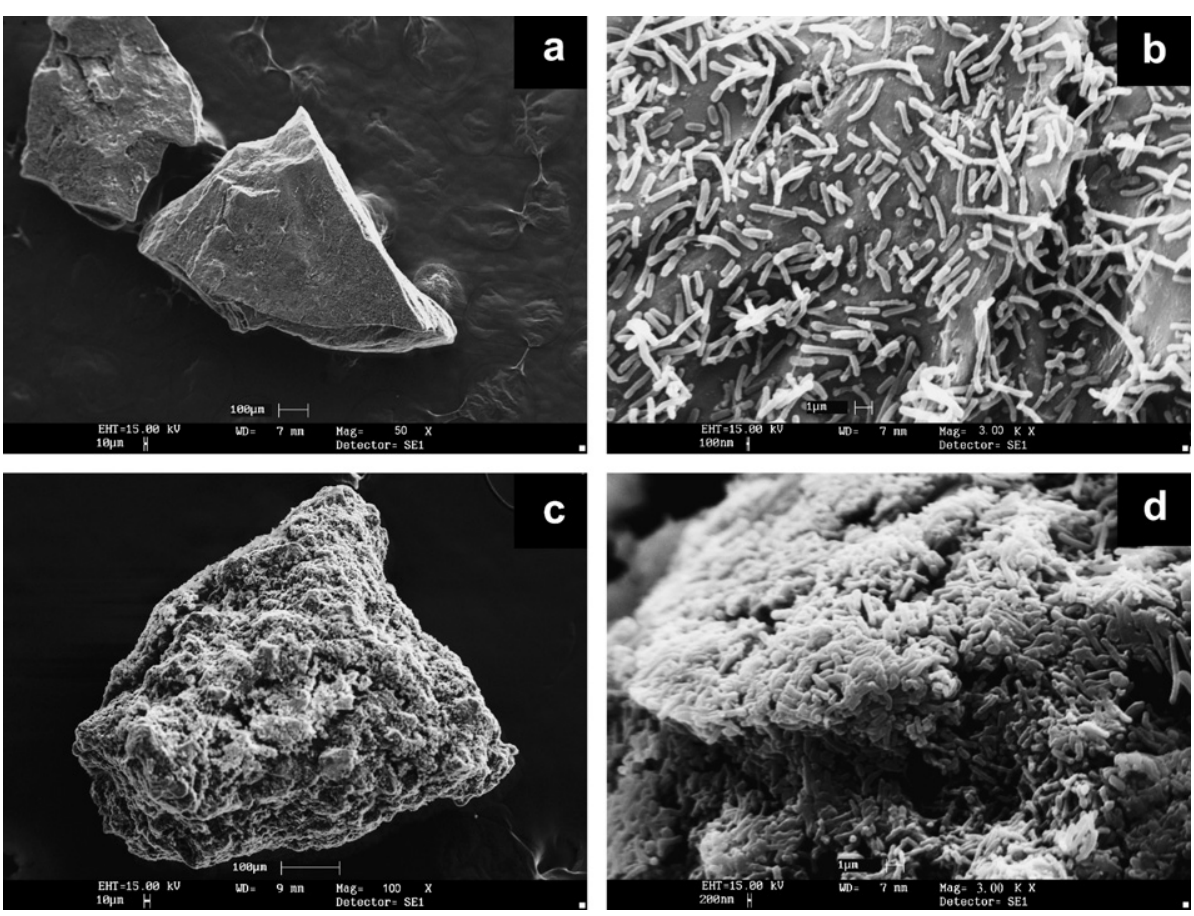

Fig. 5 - SEM images of biofilms developed at $36 \mathrm{~h}$ in R3: (a) overview and (b) cells attaching on the surface of GAC, and in R4: (c) overview and (d) cells attaching on the surface of GAC. 


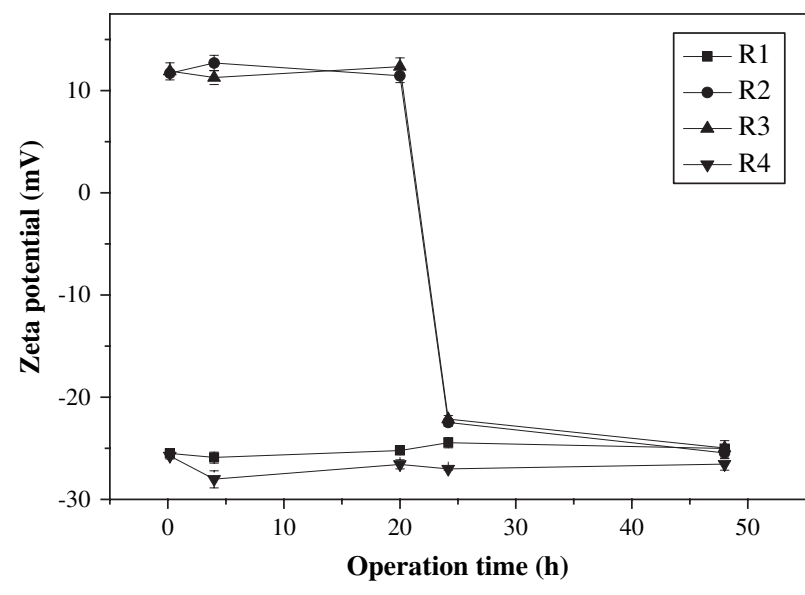

Fig. 6 - Variation of the zeta potential of microbial culture during and after the acid incubation.

difference in particle size. The particles used for zeta potential measurement had an average diameter of $1.8 \mu \mathrm{m}$ and $3.1 \mu \mathrm{m}$ in the previous [9] and present studies, respectively (measured by the Zeta potential analyzer). The GAC used in the present study had a measured zeta potential of $2.7 \mathrm{mV}$ at a $\mathrm{pH}$ of 5.5. However, the zeta potential of GAC was found to increase significantly to $76.1 \mathrm{mV}$ at a $\mathrm{pH}$ of 2.0 .

According to the DLVO (hypothesised by Derjaguin, Landau, Verwey, and Overbeek) theory [19,22], acid incubation resulted in a decrease in electrostatic repulsion between microbial cells due to a relatively small amount of charges carried on the surface of cells. As a result, the van der Waals forces are predominant, which could result in greater adsorption by allowing microbial interaction of cell to cell and hence irreversible adhesion. In the analysis of surface charges, cells and GAC both having much larger positive surface potentials at a $\mathrm{pH}$ of 2 , exhibited much greater electrostatic repulsion and underwent profound inhibition of cell adhesion to GAC by strong electrostatic repulsive forces. In contrast, since the measurement of zeta potentials showed that microbial cells and GAC carried negative surface charges and positive charges, respectively at a $\mathrm{pH}$ of 5.5 , the cell adhesion to GAC was more favorable, because of opposite charge adsorption. These adsorbed cells colonized on the surface of GAC and developed into continuous biofilms rapidly as illustrated in Fig. 5.

The irreversible aggregation established between cells during the acid incubation did not break with the termination of acid incubation. It was noted that the electrostatic repulsive forces present in the aggregates was resumed, and even larger than the original level due to the shortened distance between cells in the microbial aggregates. This indicates that there were some other forces maintaining the irreversible adsorption. Previous studies showed that microbial granulation is a process associated with the production and accumulation of ECP $[24,25]$. The ECP excreted can mediate both cohesion and adhesion of cells and play a crucial role in maintaining structural integrity of microbial matrix. It had been reported that ECP composition could affect the hydrophobic properties of cellular surface which also affected microbial immobilization. Examination of ECP and associated changes in hydrophobicity was therefore conducted during the acid incubation and thereafter.

3.2.2.2. Extracellular polymers and hydrophobicity. ECP variation with the cell immobilization process is depicted in Fig. 7. The ECP consist mainly of polysaccharides and proteins which contribute to microbial adhesion $[9,24]$. The changes of environmental $\mathrm{pH}$ caused an enhanced production of ECP, especially proteins. Compared with the stabilized ECP production and composition in R1, ECP content increased substantially with the acid incubation, from $66 \mathrm{mg} / \mathrm{g}$-VSS to $136 \mathrm{mg} / \mathrm{g}$-VSS in R2, accompanying with an increased ratio of proteins to polysaccharides from 0.2 to 0.5 .

These findings imply that changes in ECP contents and composition observed during the acid incubation might be a physiological response of microbial cells to survive the stressful culture conditions. However, this phenomenon had been reported in a previous study that the increased ECP, presumably resulted from the passive leakage of intracellular substance at least partially as DNA, was detectable in the bulk solution and around the surface of microbial cells [9].

A concomitant increase in ECP production was observed with the initiation of microbial colonization in all reactors. For example, ECP content stepped up rapidly from $136 \mathrm{mg} / \mathrm{g}$-VSS at $80 \mathrm{~h}$ to $258 \mathrm{mg} / \mathrm{g}$-VSS at $139 \mathrm{~h}$ in R2 and at the same time microbial aggregates were developed into granules. These findings suggest that, in contrast to dispersed cells, ECP produced by adhered cells was inclined to build up as a part of structural components of granules or biofilms, due to the blocking of product transfer. Compared to a consistent production ratio of proteins and polysaccharides throughout the studies in $\mathrm{R} 1$ and $\mathrm{R} 4$, the ratio resumed to an original level of 0.2 in R2 and R3 after 130 h of the operation, suggesting that microbial cells subjected to the acidification had secreted ECP just like normal cells and that similar ECP components were excreted by the dispersed and aggregated cells.

The measurement of contact angle, which represents the hydrophobic properties of microbial cells, showed that the cellular hydrophobicity was in good agreement with the evolution of ECP composition. Fig. 8 demonstrates typical

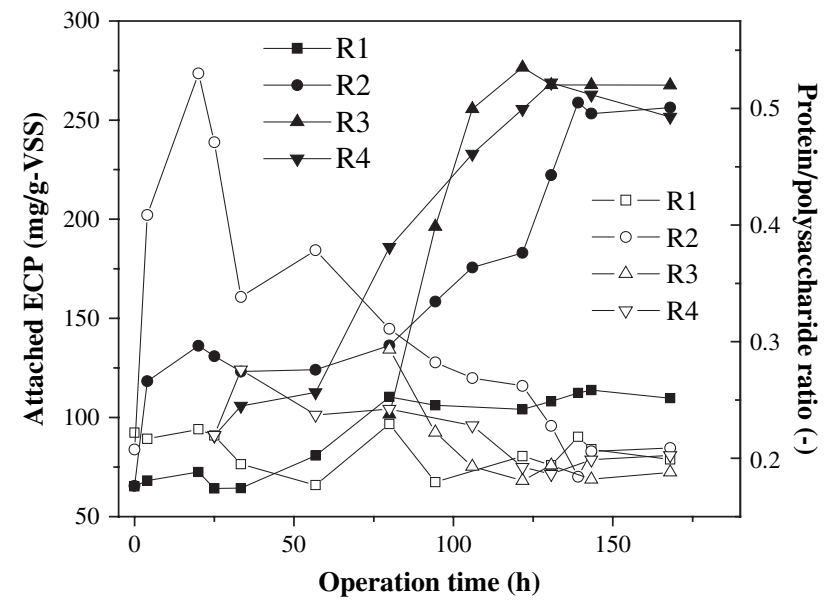

Fig. 7 - Production of extracellular polymers (solid symbols) and variation of proteins/polysaccharides ratio (open symbols). 


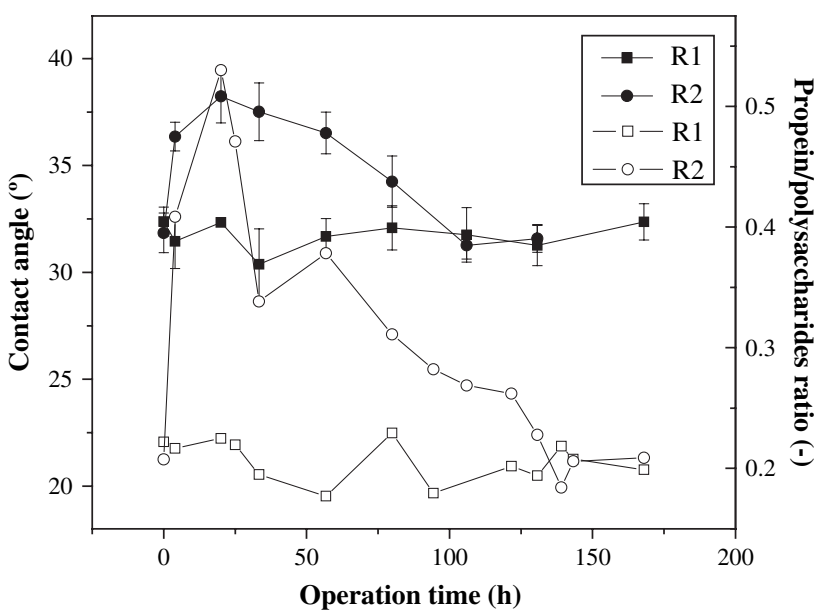

Fig. 8 - Variation of the ratio of proteins to polysaccharides (open symbols) and contact angle (solid symbols).

time-course profiles of contact angle and protein/polysaccharide ratio of sludge cultivated in $\mathrm{R} 1$ and $\mathrm{R} 2$. The contact angle increased from $31^{\circ}$ to $38^{\circ}$, corresponding to the increase in protein/polysaccharide ratios from 0.2 to 0.5 , and then resumed to $31^{\circ}$ with the reduction in protein/polysaccharide ratio. It is likely that cell hydrophobicity was not influenced directly by the culture $\mathrm{pH}$, but was a function of the ECP composition. These findings correspond to the previous studies which showed that hydrophobicity of the cellular surface was inversely correlated to the polysaccharide content, but positively to the protein proportion [26-29].

Based on the current knowledge built on methanogen granulation, short-range interaction forces like polymer bonding or hydrophobic interaction would become crucial when a cell approaches another one at a certain distance (primary minimum). ECP in aggregates is hypothesized to bridge two neighboring cells physically to each other as well as with other inert particles, and settle out as aggregates. Acid incubation stimulated the production of ECP serving as a bio-glue to facilitate cell-to-cell interaction and further strengthen aggregate structure through formation of a polymeric matrix. Microscopic observation provided visual evidence that ECP was present around the surface of hydrogen-producing granules during the initial stage of granulation in a CSTR [9]. Improved proportion of proteins in ECP resulted in a more hydrophobic environment where irreversible adhesion of microbial cells might occur. Theoretically, increasing the hydrophobicity of cell surfaces would cause a corresponding decrease in the excess Gibbs energy of the surface, which in turn promotes cellto-cell interaction and further servers as a driving force for cell self-separation from liquid phase [16]. The experimental results obtained from the present study are consistent with the reported findings.

Like biofilm development, granules are formed following a dynamic process wherein microbial attachment, detachment and growth involved $[18,20]$. Enhanced cell ECP production and hydrophobic property may improve and strengthen inter-cell structural affiliation. As illustrated in Fig. 3a, granules had a loose structure and flocky appearance in R1. Cell detachment might prefer to occur on such type of granules compared with compact and dense granules developed in R2. In fact, a relatively longer period for granule and biofilm development had been observed in R1 and R4 due to the absence of acidification stimulation. This substantiated the contribution of the ECP and hydrophobic properties of microbial cells to microbial granulation process and biofilm development.

\subsection{Reactor performance}

In cell-immobilized processes, reactor startup period, organic loading capability and corresponding substrate conversion rate are the most important indices for reactor performance evaluation. In a specific case of biohydrogen production, hydrogen production efficiency is also a crucial consideration. As demonstrated earlier, biofilm particles and acid-induced granules were noted in a very short period, generally less than $92 \mathrm{~h}$. To further evaluate reactor performance, biomass accumulation with cell immobilization and concomitant hydrogen production as well as glucose loading and utilization are presented in Fig. 9. Influent glucose concentration was maintained at $10 \mathrm{~g} / \mathrm{L}$ in all reactors throughout the study, whereas HRT was shortened step by step from $2 \mathrm{~h}$ to $0.25 \mathrm{~h}$, corresponding to an OLR of 5-40 g-glucose/L h. After reaching steady-state conditions (as evidenced by consistent biogas production and more than $90 \%$ glucose conversion rate), the reactor organic loading was increased through step shortening the HRT.

Sodium hydroxide was supplemented automatically in the present systems to control the culture $\mathrm{pH}$ at a consistent level. A high loading of up to $40 \mathrm{~g}$-glucose/ $\mathrm{L}$ required dosing of a large amount of concentrated $\mathrm{NaOH}$ to neutralize organic acid produced during the hydrogen fermentation. However, system upset occurred, since sodium hydroxide added was unable to get diluted rapidly and distribute evenly throughout the reactor at a higher OLR. Sodium bicarbonate, as an alternative to strong alkali, was supplemented into the feed solution with a concentration of $5 \mathrm{~g} / \mathrm{L}$ since $197 \mathrm{~h}$. Thereafter, less $\mathrm{NaOH}$ was required for culture $\mathrm{pH}$ adjustment and the reactors could perform stably. Immobilized-cell bed layer was controlled at a height of $48 \mathrm{~cm}$ and superfluous biomass was removed manually to prevent system upset due to the biomass accumulation in the settling zone.

Biogas production was noted along with the continuous feeding in R1 and R4, while biogas production was retarded for about $24 \mathrm{~h}$ in R2 and R3, due to the inhibition of acidification on microbial activity (Fig. 9a). Biogas production increased substantially after the HRT was shortened from $12 \mathrm{~h}$ to $2 \mathrm{~h}$ at $72 \mathrm{~h}$ and stabilized at around $102-120 \mathrm{~h}$ in all reactors except R1, in which consistent biogas production was not observed until the formation of granular sludge at $346 \mathrm{~h}$. After steady-state conditions were reached, the granule-based reactor and biofilm-based reactor indicated almost similar performance in hydrogen production at the same HRT condition. The biogas consisted of hydrogen and carbon dioxide throughout the study in all reactors. Hydrogen content increased slightly with the reduction in HRT from $2 \mathrm{~h}$ to $0.25 \mathrm{~h}$ in all the reactors, accounting for 53-64\% of the total biogas in the first of $197 \mathrm{~h}$ (Fig. 9b). A significant decrease in hydrogen content, from $63.80 \pm 0.75 \%$ to $42.35 \pm 0.66 \%$ was found after 


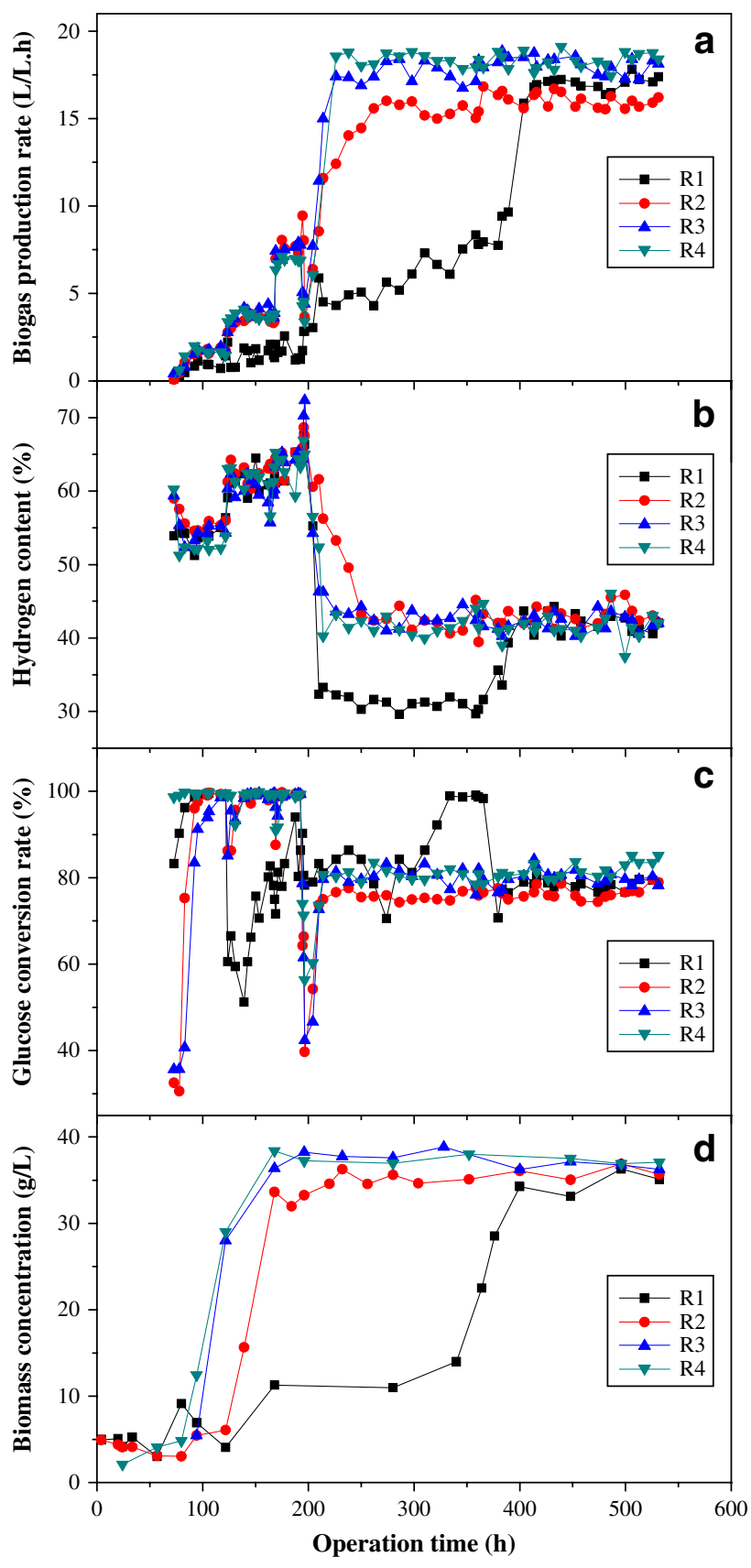

Fig. 9 - Reactor performances in terms of biogas production rate (a), hydrogen content (b), glucose conversion rate (c), and biomass retention (d).

adding $\mathrm{NaHCO}_{3}$ as alkaline buffer as the reactors were operated at an HRT of $0.25 \mathrm{~h}$. As tabulated in Table 2, the hydrogen yields increased in all reactors as the HRT was shortened from $2 \mathrm{~h}$ to $0.5 \mathrm{~h}$, but decreased slightly with the further reduction in HRT, achieving the respective maximum values of 1.83 and $1.72 \mathrm{~mol}-\mathrm{H}_{2} / \mathrm{mol}$-glucose for the granular sludge and biofilm sludge. Hydrogen production rates increased substantially with decreasing HRT, and reached the respective peaks of 6.98 and $7.49 \mathrm{~L}-\mathrm{H}_{2} / \mathrm{L} \mathrm{h}$ at the shortest HRT of $0.25 \mathrm{~h}$ in granule-based reactors and biofilm-based reactors. Shortening HRT to $0.25 \mathrm{~h}$, however, caused a substantial decrease in glucose conversion rate to a level of around $80 \%$, which was much lower in contrast to nearly $100 \%$ glucose conversion rate at HRT ranging from $2 \mathrm{~h}$ to $0.5 \mathrm{~h}$ (Fig. 9c).

A major benefit of cell immobilization is the enhancement of biomass retention. As presented in Fig. 9d, the mean biomass concentration was computed from the quantity of immobilized biomass over the reactor volume $(1.4 \mathrm{~L})$. Biomass retention increased significantly since the appearance of biofilms and granules, and reached a consistent level of 34-38 g-VSS/L at around $170 \mathrm{~h}$ in all reactors except $\mathrm{R} 1$ wherein stable biomass retention was not obtained after $400 \mathrm{~h}$ of operation. The ability to retain a large amount of immobilized biomass allowed the superior hydrogen production rate to be accomplished in those column-shaped reactors. Lee et al. [30] obtained a hydrogen production rate of $7.3 \mathrm{~L} / \mathrm{L} \mathrm{h}$ in a carrier-induced granular sludge bed system, while the performance of other hydrogen production systems using biofilm sludge or granular sludge appeared to less efficient with hydrogen production rate in the range of $0.15-2.36 \mathrm{~L} / \mathrm{Lh}$ [8,11,31-34]. The maximum hydrogen production rate achieved in the present system was $7.5 \mathrm{~L} / \mathrm{L} \mathrm{h}$, which is comparable to that obtained by Lee et al. [30] and is much higher compared with those obtained in the other systems aforementioned. It is noted that the present hydrogen production rate is also higher comparing with $3.2 \mathrm{~L} / \mathrm{L} \mathrm{h}$ obtained in the CSTR system containing granular sludge in a previous study [9]. This seems to suggest that the column-shaped reactor favors hydrogen production in contrast to the CSTR system, due to elevated biomass retention. However, the highest hydrogen production rate achieved so far at $15.3 \mathrm{~L} / \mathrm{Lh}$ was reported by $\mathrm{Wu}$ and his team [2] in a granule-based CSTR system, indicating that besides reactor configuration, operating parameters and other factors also influenced biohydrogen production. For a given reactor volume of $1.4 \mathrm{~L}$, effective volume being occupied by the immobilized sludge was only $0.6 \mathrm{~L}$. This led to the conclusion that it is possible to produce biohydrogen at a much higher rate with appropriate reactor design.

\subsection{Implications for research and engineering}

A rapid approach of acid incubation initially developed in a CSTR [9] to initiate the granulation of hydrogen-producing bacteria is validated in terms of compatibility to the columnshaped upflow reactors, the most popular configuration used in the immobilized-cell processes. The successful application of acidification is based on the facts that the hydrogen-producing bacteria mainly consisting of Clostridium species form endospores which can be considered "survival structures" developed by these bacteria under a stressful environment. The microbial culture used in the present study was collected from an anaerobic digester. Applicability of the acid incubation approach developed in this work to other inocula from different natural sources such as compost and soil remains unclear and further testing on these inocula is hence recommended from an engineering and application perspective. The process has a rapid startup period of granulation rendering a cost competitive operation.

Lowering culture $\mathrm{pH}$ to 2.0 immediately altered bacterial surface charges and created a benign electrostatic environment for microbial aggregation. Although a similar trend was observed on a same inoculum in the CSTR and AFBRs that 
Table 2 - Hydrogen production performance of granule-based and biofilm-based reactors

\begin{tabular}{|c|c|c|c|c|c|c|c|c|}
\hline \multirow[t]{2}{*}{ HRT (h) } & \multicolumn{2}{|c|}{$\begin{array}{c}\text { Glucose conversion } \\
\text { rate }(\%)\end{array}$} & \multicolumn{2}{|c|}{ Hydrogen content (\%) } & \multicolumn{2}{|c|}{$\mathrm{H}_{2}$ yield $(\mathrm{mol} / \mathrm{mol})$} & \multicolumn{2}{|c|}{$\mathrm{H}_{2}$ production rate $(\mathrm{L} / \mathrm{L} \mathrm{h}$ ) } \\
\hline & Granule $^{a}$ & Biofilm $^{b}$ & Granule & Biofilm & Granule & Biofilm & Granule & Biofilm \\
\hline 2 & $99.28 \pm 0.27$ & $98.14 \pm 2.00$ & $55.55 \pm 0.46$ & $53.79 \pm 1.36$ & $1.44 \pm 0.11$ & $1.37 \pm 0.19$ & $0.97 \pm 0.07$ & $0.91 \pm 0.10$ \\
\hline 1 & $99.00 \pm 0.73$ & $99.26 \pm 0.19$ & $62.51 \pm 0.93$ & $60.05 \pm 1.44$ & $1.64 \pm 0.08$ & $1.69 \pm 0.05$ & $2.20 \pm 0.10$ & $2.28 \pm 0.06$ \\
\hline 0.5 & $99.30 \pm 0.31$ & $99.13 \pm 0.04$ & $64.09 \pm 1.55$ & $63.65 \pm 1.25$ & $1.83 \pm 0.09$ & $1.72 \pm 0.13$ & $4.93 \pm 0.25$ & $4.62 \pm 0.36$ \\
\hline 0.25 & $77.38 \pm 1.53$ & $80.71 \pm 0.80$ & $42.72 \pm 0.72$ & $41.98 \pm 0.50$ & $1.66 \pm 0.04$ & $1.71 \pm 0.03$ & $6.98 \pm 0.30$ & $7.49 \pm 0.20$ \\
\hline
\end{tabular}

a Data (average value \pm standard deviation) at HRTs of 2-0.5 h were derived from R2 only, while data at a HRT of $0.25 \mathrm{~h}$ from R1 and R2.

b Data (average value \pm standard deviation) were derived from R3 and R4.

charge numbers reduced with the acid incubation, zeta potentials increased from $-11.6 \mathrm{mV}$ to $-3.5 \mathrm{mV}$ in the CSTR, while from -25.4 to 11.9 in the AFBRs. As stated earlier, the most plausible factor resulting in an inconsistent measurement would appear to be the difference in floc sizes. This also indicates that culture properties have an important influence on the bacterial electrostatic environment. A pretest determining isoelectric $\mathrm{pH}$ of different hydrogen-producing cultures is recommended to minimize the electrostatic repulsive forces. Since the improvement of bacterial surface physicochemical characteristics was able to be achieved immediately with the acid incubation, a 24-h incubation time used in the present work may be shortened, which would help activate hydrogen-producing bacteria from the acid incubation.

The mechanisms of $\mathrm{pH}$ change to accelerate the immobilization process of Clostridia-like bacteria remain unclear. Presumably, either $\mathrm{pH}$ change did stimulate the growth of immobilized hydrogen-producing bacteria, or improved adhesive properties of cells, due to the acidification, indirectly resulted in less cell detachment occurring on immobilized particles, or both mechanisms functioned. The denaturing gradient gel electrophoresis profile showed that only one strain of bacterium was predominant over the microbial population of the acclimated seed sludge [10]. Due to its rapid selfflocculated properties, identification and purification of this strain of bacterium would help to provide microbial information to understand microbial immobilization. Purified bacterium is likely to serve as a biological flocculant in the processes of water treatment and inducing reagent for microbial immobilization. As the microbial nuclei play a critical role in the formation of granules, it is anticipated that methanogenic granulation is accelerated via rapid formation of acidogen-rich starting nuclei for the further development of methanogens. This hypothesis is supported experimentally by the finding obtained by Vanderhaegen et al. [35] who stated that sugar fermentative acidogens formed sufficient biomass and polymers to act as "nucleation" centers in which the rest of the methanogenic associations could develop.

\section{Conclusions}

A novel approach to initiate rapid immobilization of hydrogenproducing microbial culture in upflow column-type reactors was demonstrated with or without support carriers. A 24-h period of acidification on the microbial culture at $\mathrm{pH} 2.0$ substantially accelerated the granulation, but not biofilm formation. In contrast to a much longer time $(346 \mathrm{~h}$ ) required for granulation of the culture without acidification, acid incubation was able to initiate a rapid formation of granules within $92 \mathrm{~h}$. The use of support media as starting nuclei may result in rapid formation of biofilms without acidification within $36 \mathrm{~h}$. Although microbial activity was inhibited by acid incubation for about $78 \mathrm{~h}$, resulting in a retarded formation of biofilms of the acidified culture, these acidified biofilms were able to develop much faster in the subsequent observation.

The experimental results indicated that reducing culture $\mathrm{pH}$ resulted in improvement in surface physicochemical properties of the culture favoring microbial adhesion and immobilization. Zeta potential increased from $-25.3 \mathrm{mV}$ to $11.9 \mathrm{mV}$, hydrophobicity in terms of contact angle improved from $31^{\circ}$ to $38^{\circ}$ and production of extracellular polymers increased from $66 \mathrm{mg} / \mathrm{g}$-VSS to $136 \mathrm{mg} / \mathrm{g}$-VSS. Formation of granules and biofilms allowed the hydrogen-producing biosystems to be operated at a very short HRT of up to $0.25 \mathrm{~h}$, corresponding to an OLR of $40 \mathrm{~g}$-glucose/L $\mathrm{h}$. The highest hydrogen production rates of $6.98 \mathrm{~L} / \mathrm{L} \mathrm{h}$ and $7.49 \mathrm{~L} / \mathrm{L} \mathrm{h}$ were achieved in granule-based and biofilm-based reactors, respectively, at the shortest HRT condition, considerably higher than those reported by others.

\section{R E F E R E N C E S}

[1] Das D, Veziroglu TN. Hydrogen production by biological processes: a survey of literature. Int J Hydrogen Energy 2001; 26(1):13-28.

[2] Wu SY, Hung CH, Lin CN, Chen HW, Lee AS, Chang JS. Fermentative hydrogen production and bacterial community structure in high-rate anaerobic bioreactors containing silicone-immobilized and self-flocculated sludge. Biotechnol Bioeng 2006;93(5):934-46.

[3] Show KY, Zhang ZP, Tay JH, Liang DT, Lee DJ, Jiang WJ. Production of hydrogen in a granular sludge-based anaerobic continuous stirred tank reactor. Int J Hydrogen Energy 2007; 32(18):4744-53.

[4] Zhang ZP, Show KY, Tay JH, Liang DT, Lee DJ. Enhanced continuous biohydrogen production by immobilized anaerobic microflora. Energy Fuels 2008;22:87-92.

[5] Zhang Z-P, Show K-Y, Tay J-H, Liang DT, Lee D-J. Biohydrogen production with anaerobic fluidized bed reactors - a comparison of biofilm-based and granule-based systems. Int J Hydrogen Energy 2008;33(5):1559-64.

[6] Chang FY, Lin CY. Biohydrogen production using an up-flow anaerobic sludge blanket reactor. Int J Hydrogen Energy 2004; 29(1):33-9. 
[7] Fang HHP, Liu H, Zhang T. Characterization of a hydrogenproducing granular sludge. Biotechnol Bioeng 2002;78(1): 44-52.

[8] Oh YK, Kim SH, Kim MS, Park S. Thermophilic biohydrogen production from glucose with trickling biofilter. Biotechnol Bioeng 2004;88(6):690-8.

[9] Zhang ZP, Show KY, Tay JH, Liang DT, Lee DJ, Jiang WJ. Rapid formation of hydrogen-producing granules in an anaerobic continuous stirred tank reactor induced by acid incubation. Biotechnol Bioeng 2007;96(6):1040-50.

[10] Zhang ZP, Show KY, Tay JH, Liang DT, Lee DJ, Jiang WJ. Effect of hydraulic retention time on biohydrogen production and anaerobic microbial community. Process Biochem 2006; 41(10):2118-23.

[11] Zhang ZP, Tay JH, Show KY, Yan R, Liang DT, Lee DJ, et al. Biohydrogen production in a granular activated carbon anaerobic fluidized bed reactor. Int J Hydrogen Energy 2007; 32(2):185-91.

[12] Dubois M, Gilles KA, Hamilton JK, Rebers PA, Smith F. Colorimetric method for determination of sugars and related substrates. Anal Chem 1956;28(3):350-6.

[13] APHA. Standard methods for the examination of water and wastewater. 20th ed. Washington DC, USA: American Public Health Association; 1998.

[14] Tay JH, Liu QS, Liu Y. Microscopic observation of aerobic granulation in sequential aerobic sludge blanket reactor. J Appl Microbiol 2001;91(1):168-75.

[15] Show KY, Wang Y, Foong SF, Tay JH. Accelerated start-up and enhanced granulation in upflow anaerobic sludge blanket reactors. Water Res 2004;38(9):2293-304.

[16] Liu Y, Xu HL, Yang SF, Tay JH. Mechanisms and models for anaerobic granulation in upflow anaerobic sludge blanket reactor. Water Res 2003;37(3):661-73.

[17] Noyola A, Moreno G. Granule production from raw waste activated-sludge. Water Sci Technol 1994;30(12):339-46.

[18] Tijhuis L, Vanloosdrecht MCM, Heijnen JJ. Formation and growth of heterotrophic aerobic biofilms on small suspended particles in airlift reactors. Biotechnol Bioeng 1994;44(5): 595-608.

[19] Schmidt JE, Ahring BK. Granular sludge formation in upflow anaerobic sledge blanket (UASB) reactors. Biotechnol Bioeng 1996;49(3):229-46.

[20] Nicolella C, van Loosdrecht MCM, Heijnen SJ. Particle-based biofilm reactor technology. Trends Biotechnol 2000;18(7): 312-20.

[21] Hulshoff Pol LW, de Castro Lopes SI, Lettinga G, Lens PNL. Anaerobic sludge granulation. Water Res 2004;38(6):1376-89.
[22] Tay JH, Tay STL, Liu Y, Show KY, Ivanov V. Biogranulation technologies for wastewater treatment. Oxford: Elsevier Science; 2006.

[23] Wang Y, Show KY, Tay JH, Sim KH. Effects of cationic polymer on start-up and granulation in upflow anaerobic sludge blanket reactors. J Chem Technol Biotechnol 2004; 79(3):219-28.

[24] Liu YQ, Liu Y, Tay JH. The effects of extracellular polymeric substances on the formation and stability of biogranules. Appl Microbiol Biotechnol 2004;65(2):143-8.

[25] Zhou WL, Imai T, Ukita M, Sekine M, Higuchi T. Triggering forces for anaerobic granulation in UASB reactors. Process Biochem 2006;41(1):36-43.

[26] Houghton JI, Quarmby J. Biopolymers in wastewater treatment. Curr Opin Biotechnol 1999;10(3):259-62.

[27] Jorand F, Guicherd P, Urbain V, Manem J, Block JC. Hydrophobicity of activated-sludge flocs and laboratorygrown bacteria. Water Sci Technol 1994;30(11):211-8.

[28] Liao BQ, Allen DG, Droppo IG, Leppard GG, Liss SN. Surface properties of sludge and their role in bioflocculation and settleability. Water Res 2001;35(2):339-50.

[29] Bonet R, Simon-Pujol MD, Congregado F. Effects of nutrients on exopolysaccharide production and surface properties of Aeromonas salmonicida. Appl Environ Microbiol 1993;59(8): 2437-41.

[30] Lee KS, Wu JF, Lo YS, Lo YC, Lin PJ, Chang JS. Anaerobic hydrogen production with an efficient carrier-induced granular sludge bed bioreactor. Biotechnol Bioeng 2004;87(5): 648-57.

[31] Rachman MA, Nakashimada Y, Kakizono T, Nishio N. Hydrogen production with high yield and high evolution rate by self-flocculated cells of Enterobacter aerogenes in a packed-bed reactor. Appl Microbiol Biotechnol 1998;49(4): 450-4.

[32] Chang JS, Lee KS, Lin PJ. Biohydrogen production with fixed-bed bioreactors. Int J Hydrogen Energy 2002;27(11-12): 1167-74.

[33] Kumar N, Das D. Continuous hydrogen production by immobilized Enterobacter cloacae IIT-BT 08 using lignocellulosic materials as solid matrices. Enzyme Microb Technol 2001;29(4-5):280-7.

[34] Wu SY, Lin CN, Chang JS. Hydrogen production with immobilized sewage sludge in three-phase fluidized-bed bioreactors. Biotechnol Prog 2003;19(3):828-32.

[35] Vanderhaegen B, Ysebaert E, Favere K, Vanwambeke M, Peeters T, Panic V, et al. Acidogenesis in relation to in-reactor granule yield. Water Sci Technol 1992;25(7):21-30. 